\title{
Strong Coincidence Between Slow Wave Sleep and Low AHI is Explainable by the High Instability of Slow Wave Sleep to Obstructive Apnea Exposure
}

\author{
I. PEREGRIM ${ }^{1}$, S. GREŠOVÁ ${ }^{1}$, J. ŠTIMMELOVÁ ${ }^{1}$, I. BAČOVÁ ${ }^{1}$, B. L. FULTON ${ }^{2}$, \\ D. TOKÁROVÁ ${ }^{1}$, M. GÁBOROVÁ ${ }^{1}$, A. BRANDEBUROVÁ ${ }^{1}$, V. DONIČOVÁ JR ${ }^{3}$, \\ S. RUSNÁKOVÁ ${ }^{3}$, Z. TOMORI ${ }^{1 \dagger}$, V. DONIČ ${ }^{1}$ \\ ${ }^{\dagger}$ Deceased.
}

${ }^{1}$ Department of Medical Physiology, Faculty of Medicine, P. J. Šafárik University, Košice, Slovakia, ${ }^{2}$ Department of Biology, Belmont College, Tennessee, USA, ${ }^{3}$ Department of Pathological Physiology, Faculty of Medicine, P. J. Šafárik University, Košice, Slovakia

Received September 14, 2018

Accepted May 21, 2019

Epub Ahead of Print August 19, 2019

\section{Summary}

It is well known that in patients with obstructive sleep apnea syndrome (OSAS) the apnea-hypopnea index (AHI) is significantly decreased during slow wave sleep (SWS). It used to be explained by the ability of SWS to stabilize the upper airways against collapse. Another explanation, which is the focus of the current study, is that it is just a result of high instability of SWS to obstructive apnea exposure, i.e. high susceptibility of SWS to transition into lighter sleep stages during exposure to obstructive apneas. A retrospective chart review was performed on 560 males who underwent an overnight polysomnography. Two hundred and eighty-seven patients were eligible for the study. They were divided into 3 groups according to different AHI level. All three groups had a higher SWS occurrence in the lateral position than in the supine position. A special fourth group of patients was created with severe OSAS in the supine position but with very mild OSAS in the lateral position. This group had, in the lateral position, (A) higher AHI in NREM sleep (4.1 $\pm 3.1 / \mathrm{h}$ vs. $0.7 \pm 1.2 / \mathrm{h}, \mathrm{p}<0.001$ ) as well as (B) higher swS occurrence $(27.7 \pm 15.0 \%$ vs. $21.4 \pm 16.2 \%$ of NREM sleep, $p<0.05)$, than the group with the lowest $A H I$ in the study, i.e. $A H I<5 / h$ in NREM sleep. These data suggest that strong coincidence between SWS and low AHI is the result of the high instability of SWS to obstructive apnea exposure. The data also support the presence of SWS-rebound in OSAS patients in the lateral body position.

\section{Key words}

Obstructive sleep apnea • NREM sleep • Slow-wave sleep • Body position • Position of upper airways

\section{Corresponding author}

I. Peregrim, Department of Medical Physiology, Faculty of Medicine, P. J. Šafárik University, Trieda SNP 1, 04011 Košice, Slovakia. E-mail: igor.peregrim1@upjs.sk

\section{Introduction}

Obstructive sleep apnea syndrome (OSAS) is a common disorder characterized by repetitive upperairway collapse during sleep. It has important consequences such as increased risk of cardiovascular disease or motor vehicle accidents (Garvey et al. 2015). The presence and severity of OSAS is typically determined by frequency of apneas and hypopneas per hour of sleep (apnea-hypopnea index, AHI). It is well known that AHI is significantly decreased during slow wave sleep (SWS) (Ratnavadivel et al. 2009, Koutsourelakis et al. 2016, Bittencourt et al. 2001). There is an attempt to explain it by higher upper-airway muscle activity and/or by lower upper-airway collapsibility during this stage of sleep (McSharry et al. 2013, Carberry et al. 2016). However, it is possible to simply explain it just by increased instability of SWS to obstructive apnea exposure, i.e. high susceptibility of SWS to transition into 
lighter sleep stages during exposure to obstructive apneas. As it is well known, severe OSAS decreases occurrence of SWS and continuous positive airway pressure (CPAP) treatment of OSAS causes SWS rebound (Brillante et al. 2012, Issa and Sullivan 1986). This suggests that disadvantageous shapes of the upper airways for breathing during sleep, due to some body positions (especially supine) (Oksenberg et al. 2000) as well as of head or bite (Isono et al. 2005, Isono et al. 2004, Zhu et al. 2017), result in higher AHI (and more severe obstructive episodes) and finally in lower occurrence of SWS and on the other hand, beneficial shapes of upper airways result in lower AHI (and less severe obstructive episodes) and rebound of SWS. The aim of this study was, therefore, to investigate the relationship between SWS occurrence and different body positions in patients with different OSAS severity and thus to detect both (A) low occurrence of SWS in supine body position (which represents disadvantageous shapes of the upper airways for breathing during sleep) and (B) rebound of SWS in lateral body position (which represents beneficial shapes of the upper airways for breathing during sleep).

\section{Methods}

A retrospective chart review was performed on 560 males who underwent an overnight polysomno-graphy from March 2009 to June 2017. Polysomnography included three-channel electroencephalogram, two-channel electrooculogram, electrocardiogram, submental and leg electromyogram, thoracic and abdominal inductance plethysmography, nasal cannula, pulse oximeter, body position sensor (capable to determine 8 different body positions: supine, prone, right-lateral, left-lateral and 4 boundary positions, i.e. right-supine, left-supine, rightprone, left-prone), snore microphone and infrared camera (Alice 3 Diagnostic Sleep System, Phillips Respironics). Records were scored manually according to the standard criteria (Iber et al. 2007, Berry et al. 2015) using Alice Sleepware software. Patients with total sleep time duration under $200 \mathrm{~min}$, with a higher amount of central apneas than obstructive apneas during NREM sleep (NREMs) and those with NREMs duration in supine position under $15 \mathrm{~min}$ as well as those with NREMs duration in lateral body position (the sum of right-lateral, left-lateral, rightprone and left-prone position) under $15 \mathrm{~min}$ were excluded from the study $(n=273)$. The rest of the patients were eligible for the study $(\mathrm{n}=287)$. Patients were divided into three groups: 1) those with AHI in NREM sleep
(AHI-NREMs) under 5/h, 2) those with AHI-NREMs 5/h and higher but less than $30 / \mathrm{h}$ and 3) those with AHI-NREMs 30/h and higher. Females were not included in the study because they typically show a lower severity of OSAS (at least in NREMs) (Garvey et al. 2015, Peregrim et al. 2013), and, independently of this, also a higher occurrence of SWS (Redline et al. 2004). Each value in the study is written as a mean \pm SD. Wilcoxon signed ranks test or Mann-Whitney $U$ test were used for statistical analysis. Moreover, an analysis of covariance (ANCOVA) using the general linear model procedure was performed to test the effect of both age and BMI (covariates) for SWS occurrence. $\mathrm{P}<0.05$ was considered significant. All statistics were made using SPSS statistics 17 .

\section{Results}

Both the first (AHI-NREMs $<5 / \mathrm{h}$ ) and the second $(5 / \mathrm{h} \leq \mathrm{AHI}-\mathrm{NREMs}<30 / \mathrm{h})$ group of patients reached in both lateral (i.e. right-lateral, left-lateral, right-prone and leftprone position together) and supine body position higher SWS occurrence when compared to the third (AHI-NREMs $\geq 30 / h$ ) group of patients; however, after taking both age and BMI into account, the statistical significance was not reached between the first and the third group in the lateral position (Table 1). All three groups had a higher SWS occurrence in the lateral position than in the supine position. This relationship was stronger in groups with higher AHI as follows 1.58 vs. 2.55 and vs. 2.90 (Table 1, green numbers). The patients of the third group, during NREMs, in the lateral position, reached both (A) higher AHI $(47.4 \pm 31.4 / \mathrm{h}$ vs. $32.4 \pm 18.3 / \mathrm{h}, \mathrm{p}<0.001)$ and apnea index (AI, i.e. frequency of apneas per hour of sleep; $33.2 \pm 28.7 / \mathrm{h}$ vs. $18.8 \pm 17.7 / \mathrm{h}, \mathrm{p}=0.001$ ) as well as (B) higher SWS occurrence $(14.4 \pm 16.0 \%$ vs. $9.0 \pm 11.8 \%$ of NREMs, $p<0.01$ ), than the patients of the second group reached during NREMs in the supine position (Table 1, blue numbers).

A special fourth group of patients was created with severe OSAS in the supine position but with very mild OSAS in the lateral position as follows: The second and third group were merged together and those patients were removed who reached AHI-NREMs $<30 /$ h in supine position, arousal index (ArI, frequency of arousals per hour of sleep) $<10 / \mathrm{h}$ during NREMs in supine position or AHI-NREMs $>10 / \mathrm{h}$ in lateral position. This group had, in the lateral position, (A) higher both AHI-NREMs $(4.1 \pm 3.1 / \mathrm{h}$ vs. $0.7 \pm 1.2 / \mathrm{h}, \mathrm{p}<0.001)$ and AI-NREMs $(2.0 \pm 2.4 / \mathrm{h}$ vs. $0.3 \pm 0.6 / \mathrm{h}, \mathrm{p}<0.001)$ as well as 
(B) higher SWS occurrence $\quad(27.7 \pm 15.0 \% \quad$ vs. $21.4 \pm 16.2 \%$ of NREMs, $\mathrm{p}<0.05$ ), than the first group of patients had in the lateral position (Table 2, red numbers).
The fourth group also reached the highest ratio of SWS occurrence between lateral and supine position (Table 1 and Table 2, green numbers).

Table 1. The percentage of SWS from NREMs and severity of AHI and AI during NREMs in both lateral and supine body position in groups 1,2 and 3.

\begin{tabular}{|c|c|c|c|c|c|c|c|}
\hline Group & L-SWS/NREM & S-SWS/NREM & Ratio & $\begin{array}{c}\text { AHI in L } \\
\text { in NREMs }\end{array}$ & $\begin{array}{c}\text { AHI in S } \\
\text { in NREMs }\end{array}$ & $\begin{array}{c}\text { AI in L } \\
\text { in NREMs }\end{array}$ & $\begin{array}{c}\text { AI in } \mathrm{S} \\
\text { in NREMs }\end{array}$ \\
\hline $1^{s t}$ & $\begin{array}{c}21.4 \pm 16.2 \% \\
\Theta\end{array}$ & $\begin{array}{c}13.6 \pm 16.9 \% \\
\# \\
\Theta\end{array}$ & 1.58 & $\begin{array}{c}0.7 \pm 1.2 \\
\text { OOO }\end{array}$ & $\begin{array}{c}4.2 \pm 5.9 \\
\# \# \# \\
\text { OOO }\end{array}$ & $\begin{array}{c}0.3 \pm 0.6 \\
\mathrm{OOO}\end{array}$ & $\begin{array}{c}1.7 \pm 2.9 \\
\# \# \# \\
\text { OOO }\end{array}$ \\
\hline $2^{n d}$ & 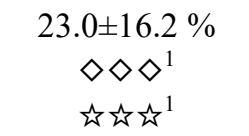 & $\begin{array}{c}9.0 \pm 11.8 \% \\
\# \# \# \\
\Delta^{2}\end{array}$ & 2.57 & $\begin{array}{c}5.7 \pm 6.7 \\
\diamond \\
\text { 论放弥 }\end{array}$ & $\begin{array}{c}32.4 \pm 18.3 \\
\# \# \# \\
\text { 论柁通 }\end{array}$ &  & $\begin{array}{c}18.8 \pm 17.7 \\
\text { \#\#\# } \\
\text { 词论场 }\end{array}$ \\
\hline $3^{r d}$ & $\begin{array}{c}14.4 \pm 16.0 \% \\
\triangle \triangle^{1} \\
\square \square^{2}\end{array}$ & $\begin{array}{c}5.0 \pm 8.0 \% \\
\# \# \# \\
\square \square{ }^{1}\end{array}$ & 2.90 & $\begin{array}{c}47.4 \pm 31.4 \\
\triangle \triangle \triangle \\
\square \square \square\end{array}$ & $\begin{array}{c}75.1 \pm 19.2 \\
\text { \#\#\# } \\
\square \square \square\end{array}$ & $\begin{array}{c}33.2 \pm 28.7 \\
\triangle \triangle \\
\square \square \square\end{array}$ & $\begin{array}{c}62.2 \pm 23.0 \\
\# \# \# \\
\square \square \square\end{array}$ \\
\hline
\end{tabular}

Group $1^{\text {st: }}$ AHI-NREMs $<5 / \mathrm{h}, \mathrm{n}$ (number of patients) $=59, \mathrm{BMI}=28.1 \pm 3.6$, age $=41.3 \pm 11.6$; Group $\mathbf{2}^{\text {nd }}$ : 5/h $\leq \mathrm{AHI}-\mathrm{NREMs}<30 / \mathrm{h}, \mathrm{n}=105$, $B M I=30.7 \pm 4.9$, age $=47.2 \pm 12.3$; Group $3^{\text {rd }}$ : AHI-NREMs $\geq 30 / h, n=123$, BMI=33.1 \pm 5.0 , age $=48.9 \pm 11.6$; BMI comparison between groups always reached $p<0.001$; age of patients in $1^{\text {st }}$ group (age1) vs. age2 reached $p<0.01$; age2 vs. age 3 reached $p>0.05$; age1 vs. age3 reached $p<0.001$; L-SWS/NREM: the \% of SWS from NREMs in lateral body position; S-SWS/NREM: the \% of SWS from NREMs in supine position; Ratio: the ratio between L-SWS/NREM and S-SWS/NREM; AHI in L in NREMs: apnea-hypopnea index (AHI) during NREMs in lateral body position; AHI in S in NREMs: AHI during NREMs in supine position; AI in L in NREMs: apnea index (AI) during NREMs in lateral body position; AI in S in NREMs: AI during NREMs in supine position; \# means the comparison of variables in one group (i.e. L-SWS/NREM vs. S-SWS/NREM, AHI in L in NREMs vs. AHI in S in NREMs, AI in L in NREMs vs. AI in S in NREMs); $\mathbf{O}$ means the comparison of the same variables between $1^{\text {st }}$ group and $2^{\text {nd }}$ group (e.g. L-SWS/NREM of $1^{\text {st }}$ group vs. L-SWS/NREM of $2^{\text {nd }}$ group); means the comparison of the same variables between $2^{\text {nd }}$ group and $3^{\text {rd }}$ group; $\square$ means the comparison of the same variables between $1^{\text {st }}$ group and $3^{\text {rd }}$ group; $\diamond$ means the comparison of variables between $1^{\text {st }}$ group in supine position and $2^{\text {nd }}$ group in lateral body position (e.g. S-SWS/NREM of $1^{\text {st }}$ group vs. L-SWS/NREM of $2^{\text {nd }}$ group); $\Delta$ means the comparison of variables between $2^{\text {nd }}$ group in supine position and $3^{\text {rd }}$ group in lateral body position; one mark (e.g. $\left.\diamond\right)$ means $p<0.05$; two marks (e.g. $\diamond \diamond)$ means $p<0.01$, three marks (e.g. $\diamond \diamond \diamond)$ means $p<0.001$; crossed mark (e.g. $\diamond)$ means $p>0.05$. ${ }^{1}$ Statistical significance was also reached after taking the covariates (age and BMI) into account (ANCOVA). ${ }^{2}$ Statistical significance was not reached after taking the covariates into account $($ ANCOVA). The effect of both age $(p<0.001)$ and BMI $(p=0.047)$ was significant.

Table 2. The percentage of SWS from NREMs and severity of AHI and AI during NREMs in both lateral and supine body position in groups 1 and 4 .

\begin{tabular}{|c|c|c|c|c|c|c|c|}
\hline Group & L-SWS/NREM & S-SWS/NREM & Ratio & $\begin{array}{c}\text { AHI in L } \\
\text { in NREMs }\end{array}$ & $\begin{array}{c}\text { AHI in S } \\
\text { in NREMs }\end{array}$ & $\begin{array}{c}\text { AI in L } \\
\text { in NREMs }\end{array}$ & $\begin{array}{c}\text { AI in S } \\
\text { in NREMs }\end{array}$ \\
\hline $1^{s t}$ & $\begin{array}{c}21.4 \pm 16.2 \% \\
\mathrm{O}^{1}\end{array}$ & $\begin{array}{c}13.6 \pm 16.9 \% \\
\# \\
\mathrm{OO}^{1}\end{array}$ & 1.58 & $\begin{array}{c}0.7 \pm 1.2 \\
\text { OOO }\end{array}$ & $\begin{array}{c}4.2 \pm 5.9 \\
\# \# \# \\
\text { OOO }\end{array}$ & $\begin{array}{c}0.3 \pm 0.6 \\
\text { OOO }\end{array}$ & $\begin{array}{c}1.7 \pm 2.9 \\
\# \# \# \\
\text { OOO }\end{array}$ \\
\hline $4^{\text {th }}$ & $27.7 \pm 15.0 \%$ & $\begin{array}{c}4.1 \pm 8.1 \% \\
\# \# \#\end{array}$ & 6.81 & $4.1 \pm 3.1$ & $\begin{array}{c}56.4 \pm 14.8 \\
\# \# \#\end{array}$ & $2.0 \pm 2.4$ & $\begin{array}{c}39.0 \pm 22.4 \\
\# \# \#\end{array}$ \\
\hline
\end{tabular}

Group $1^{\text {st: }}$ AHI-NREMs $<5 / h, n$ (number of patients)=59, BMI=28.1 \pm 3.6 , age $=41.3 \pm 11.6$; Group $4^{\text {th }}$ : AHI-NREMs $\geq 5 / h$, AHI-NREMs $\geq 30 / \mathrm{h}$ in supine position, arousal index $\geq 10 / \mathrm{h}$ during NREMs in supine position, AHI-NREMs $\leq 10 / \mathrm{h}$ in lateral body position, $\mathrm{n}=46$, BMI $=30.7 \pm 4.5$, age $=48.0 \pm 11.9$; BMI of patients in $1^{\text {st }}$ group (BMI 1) vs. BMI 4 reached $p=0.001$; age of patients in $1^{\text {st }}$ group (age1) vs. age4 reached $p<0.01$; L-SWS/NREM: the \% of SWS from NREMs in lateral body position; S-SWS/NREM: the \% of SWS from NREMs in supine position; Ratio: the ratio between L-SWS/NREM and S-SWS/NREM; AHI in L in NREMs: apnea-hypopnea index (AHI) during NREMs in lateral body position; AHI in S in NREMs: AHI during NREMs in supine position; AI in L in NREMs: apnea index (AI) during NREMs in lateral body position; AI in S in NREMs: AI during NREMs in supine position; \# means the comparison of variables in one group (i.e. L-SWS/NREM vs. S-SWS/NREM, AHI in L in NREMs vs. AHI in S in NREMs, AI in L in NREMs vs. AI in S in NREMs); 0 means the comparison of the same variables between $1^{\text {st }}$ group and $4^{\text {th }}$ group (e.g. L-SWS/NREM of $1^{\text {st }}$ group vs. L-SWS/NREM of $4^{\text {th }}$ group); one mark (e.g. \#) means p<0.05; two marks (e.g. \#\#) means $p<0.01$, three marks (e.g. \#\#\#) means $\mathrm{p}<0.001$. ${ }^{1}$ Statistical significance was reached also after taking the covariates (age and BMI) into account (ANCOVA). 


\section{Discussion}

It was found that higher AHI-NREMs is associated with lower SWS occurrence; this is true not only generally for OSAS patients, but also for their different body positions (i.e. the supine position is associated with both higher AHI and lower SWS occurrence compared to the lateral position). Our results also suggest that SWS-rebound occurs in severe OSAS patients in cases of accidental beneficial shapes of the upper airways for breathing during sleep. OSAS patients with higher AHI-NREMs (third group, AHI-NREMs $\geq 30 / \mathrm{h}$ ) reached in the lateral position (A) higher AHI-NREMs as well as (B) higher SWS occurrence, than OSAS patients with lower AHI-NREMs (second group, $5 / \mathrm{h} \leq \mathrm{HI}-\mathrm{NREMs}<30 / \mathrm{h}$ ) reached in the supine position (Table 1, blue numbers). Similarly, the fourth group of patients (severe OSAS in the supine position but very mild OSAS in the lateral position) had in the lateral position both (A) higher AHI-NREMs and (B) higher SWS occurrence, than the first group, i.e. patients with AHI-NREMs $<5 /$ h (Table 2, red numbers).

It should be emphasized that lower SWS occurrence is associated with higher age (at least in men) (Redline et al. 2004) and probably also with other factors such as higher BMI (Rao et al. 2009) or diabetes mellitus (Pallayova et al. 2010). Despite this, patients with higher AHI in the current study ( $3^{\text {rd }}$ group, $4^{\text {th }}$ group), who are also associated with higher BMI, age (Garvey et al. 2015) as well as diabetes mellitus (Reutrakul and Mokhlesi 2017), were able to reach higher SWS occurrence under certain conditions than patients with lower AHI. Surprisingly, although patients with the highest AHI ( $3^{\text {rd }}$ group) showed a lower occurrence of SWS in the supine position than patients with the lowest AHI $\left(1^{\text {st }}\right.$ group) even after considering covariates (age and $\mathrm{BMI}$ ), it was not the case in the lateral position (Table 1). This reflects the effort of OSAS patients to compensate the lack of SWS by its rebound during beneficial shapes of the upper airways.

The current study supports the following relationship: the body position (more precisely, the shape of the upper airways) influences the AHI level (as well as the severity of obstructive episodes) which subsequently influences the occurrence of SWS in NREMs. More specifically, these data suggest two effects: (A) during disadvantageous body positions (i.e. disadvantageous upper-airway shapes) for breathing, higher AHI interrupts SWS which occurrence in NREMs subsequently decreases and (B) during beneficial body positions (i.e. beneficial upper-airway shapes) for breathing, lower AHI supports SWS-rebound which imitates the effect of CPAP.

One may find the results of SWS occurrence in groups with different AHI (Table 1) somewhat strange. For example, in the group with the highest AHI, the AHI is nearly 70-times (47.4/0.7) higher in the lateral position and nearly 20-times (75.1/4.5) higher in the supine position than in the group with the lowest AHI, however, the SWS occurrence in NREMs is only 1.5-times (21.4/14.4) lower in the lateral position and 2.7-times (13.6/5.0) lower in the supine position. However, this apparent mismatch between the "rapid" increase in AHI and the "slow" decline in SWS is consistent with the existence of a rebound phenomenon. Even in the group of patients with the highest AHI, there are still some sections of sleep with normal breathing, alternatively with only snoring or mild hypopneas, which do not interrupt SWS. Naturally, these sections occur more frequently in the lateral position. Rebound phenomenon means that in patients with higher and higher AHI, SWS appears more and more in these still shorter and shorter sleep sections.

One might doubt that they are obstructive upperairway episodes that reduce SWS in sleep and not vice versa, i.e. that SWS reduces the occurrence of obstructive episodes. Differences in details exist, but there is a general opinion that it is gravity which affects the shape of the upper airways in different ways in different body positions, and this is also the cause of the higher occurrence of obstructive apneas in the supine position compared to the lateral position (Elliott et al. 2001, Joosten et al. 2015, Marques et al. 2017). Our data show that there are both high AHI and low occurrence of SWS in the supine position in all our groups. This can be explained as follows: The supine position increases, due to gravity, the occurrence of apnea episodes and these interrupt SWS; or to put it another way, SWS is unstable (i.e. it turns into lighter NREMs stages) when exposed to obstructive apneas.

Theoretically, there may also be an inverse mechanism of causal relationships. This means that during sleep, as well as subconsciously when falling asleep or awakening in the night, body position is selected to prefer lateral position for SWS instead of for lighter NREMs stages. If so, the question arises why it is necessary to protect SWS in this way against obstructive episodes. The answer seems to be that SWS is 1) more 
susceptible to obstructive episodes than lighter NREMs stages and/or 2) highly unstable to obstructive apnea exposure.

Koutsourelakis et al. (2016) found an extremely low AHI in OSAS patients during SWS compared to previous studies, i.e. $0.3 \pm 0.9$ and $0.4 \pm 1.7 / \mathrm{h}$ in supine and lateral position, respectively. They explain the difference by somewhat different study management: all patients had "at least 15 consecutive minutes of SWS". One other study (Bittencourt et al. 2001) found similarly low levels of AHI in SWS. One might suggest that such an extremely low AHI during SWS may be the result of higher upper-airway muscle activity and/or lower upperairway collapsibility during this stage of sleep. There is probably lower genioglossus (GG) activity (McSharry et al. 2013, Carberry et al. 2016, Jordan et al. 2009) and higher upper-airway collapsibility (Carberry et al. 2016) during stage 2 of NREMs (S2-NREMs) compared to SWS, however, during REM sleep (REMs), GG activity is clearly much lower (Carberry et al. 2016, Jordan et al. 2009, McSharry et al. 2014) and upper-airway collapsibility is clearly much higher (Carberry et al. 2016) compared to both SWS and S2-NREMs, which would suggest that AHI is clearly the highest during REMs. In the study of Koutsourelakis et al. (2016), mean AHI was higher in S2-NREMs $(36.5 \pm 29.1 / \mathrm{h})$ than in REMs $(35.1 \pm 31.2 / \mathrm{h}$ ) at the supine position (without statistical significance testing). This may be explained by longer apneas in REMs (i.e. by coincidence of these long apneas and high AHI in supine position) than in NREMs; as showed in our previous study (Peregrim et al. 2013). At the lateral position, the mean AHI was, on the contrary, higher in REMs $(13.5 \pm 20.1 / \mathrm{h})$ than in S2-NREMs $(12.1 \pm 19.8 / \mathrm{h})$, however, statistical significance was not reached (personal communication). These AHI data of REMs suggest that extremely low AHI during SWS can not be explained by high upper-airway muscle activity or low upper-airway collapsibility. It is possible to conclude that Koutsourelakis et al. (2016) took into account the position of the body but did not take into account (nor could take into account) all beneficial upper-airway positions and shapes (e.g. the result of beneficial positions of head or bite) which seem to result in low or even very low AHI and finally in deep NREMs, i.e. SWS.

Some other data offer different relationship between AHI and sleep stages, more specifically, that the highest AHI is in REMs, lower AHI is in S2-NREMs and the lowest AHI is in SWS (Ratnavadivel et al. 2009).
However, the highest AHI in REMs is possible to explain by general body, i.e. also upper-airway, hypotonia which seems to be a prevention against motoric manifestations of dreams as dreams are typical for REMs (for example, prevention against sleep-talking or biting a tongue). On the contrary, deeper NREMs stages show typically higher body hypotonia than lighter NREMs stages (Berry et al. 2015), which would suggest lower upper-airway muscle tone during SWS than S2-NREMs. Some studies have indeed shown the tendency of tensor palatini or even geniohyoid, i.e. upper-airway dilator muscles, to decrease in EMG activity when transitioning from lighter to deeper NREMs stages (Wiegand et al. 1990, Tangel et al. 1991, Tangel et al. 1992, Edwards and White 2011, Hicks et al. 2017). This would explain detection of higher resistance in the upper airways during SWS compared to S2-NREMs (Trinder et al. 1997). Higher upper-airway resistance causes higher negative pressure in the upper airways which together with hypercapnia stimulates the activity of the upper-airway dilator muscles but especially the GG, the muscle that is able to reach EMG activities in NREMs similar to those in wakefulness or even higher (Tangel et al. 1992, Edwards and White 2011, Hicks et al. 2017, Malhotra et al. 2004). This explains the high activity of GG during SWS.

Boudewyns et al. (2000) determined both the collapsibility and the resistance of the upper airways during NREMs in both supine and lateral body position in 10 obese patients with severe OSAS. When they focused on subgroup of six patients with subatmospheric critical-upper-airway closing pressure in lateral position, they found higher AI in supine position compared to lateral position $(p=0.03)$. Surprisingly, these patients reached higher resistance of the upper airways in lateral position than in supine position $\left(24.8 \pm 14.0 \mathrm{~cm} \mathrm{H}_{2} \mathrm{O} / \mathrm{l} / \mathrm{s}\right.$ vs. $13.6 \pm 6.0 \mathrm{~cm} \mathrm{H}_{2} \mathrm{O} / \mathrm{l} / \mathrm{s}, \mathrm{p}=0.034$, Wilcoxon signed ranks test). This could be partly explained by high resistance of the upper airways during SWS (Trinder et al. 1997) and by an abundance of this stage of sleep in lateral position as was found in the current study. Generally, this could be due to higher occurrence of deeper NREMs (i.e. also "deeper" S2-NREMs) in lateral position and higher occurrence of lighter NREMs (i.e. also "lighter" S2-NREMs) in supine position.

One might consider contradictory that together with higher upper-airway resistance (Trinder et al. 1997), the lower upper-airway collapsibility (Carberry et al. 2016) has been found in SWS compared to S2-NREMs. The same surprising results were also reached in the 
above-mentioned study of Boudewyns et al. (2000). The special subgroup of six patients had both (A) higher upper-airway resistance and (B) lower upper-airway collapsibility in the lateral position compared to the supine position (the critical-upper-airway closing pressure was $1.25 \pm 1.05 \mathrm{~cm} \mathrm{H}_{2} \mathrm{O}$ and $-2.80 \pm 1.27 \mathrm{~cm} \mathrm{H}_{2} \mathrm{O}$ in supine and lateral position, respectively; $\mathrm{p}=0.028$, Wilcoxon signed ranks test).



Fig. 1. Interrelationship between 1) beneficial positions of body, head or bite, which represent beneficial upper-airway (UA) shapes for breathing, and 2) SWS and their opposite influence on UA resistance, UA collapsibility, AHI and arousal index. ${ }^{1}$ The study of Boudewyns et al. (2000) shows that during NREMs the resistance of upper airways (UAs) can be higher in the lateral position than in the supine position in some severe OSAS patients, however, we assume that this is the result of higher occurrence of SWS (or generally, deeper NREM sleep) in the lateral position than in the supine position (see our discussion). ${ }^{2}$ Lower activity of dilator muscles means lower collapsibility of UAs because in the case of the increase of UA resistance, the dilator muscles still have enough reserve to increase their activity. ${ }^{3}$ Due to SWS hypotonia, UA dilator muscles are not able to reach the same maximal activity levels as in lighter NREMs stages which means lower ability to prevent upper-airway collapse. ${ }^{4}$ Higher activity of genioglossus means higher collapsibility of UAs because in the case of the increase of UA resistance, the genioglossus has not enough reserve to increase its activity. [1] Isono et al. 2005, Isono et al. 2004, [2] Malhotra et al. 2004, Otsuka et al. 2000, [3] Malhotra et al. 2004, [4] Oksenberg et al. 2000, Zhu et al. 2017, [5] Ratnavadivel et al. 2009, Koutsourelakis et al. 2016, Bittencourt et al. 2001, [6] Wiegand et al. 1990, Tangel et al. 1991, Tangel et al. 1992, Edwards and White 2011, Hicks et al. 2017, [7] Berry et al. 2015, [8] Trinder et al. 1997, [9] McSharry et al. 2013, Carberry et al. 2016, Hicks et al. 2017.

As seen in Fig. 1, SWS itself is likely to increase both upper-airway resistance as well as upper-airway collapsibility, however, this influence is accompanied by the opposite effect of beneficial upper-airway shapes. Suppose now that SWS increases the resistance more than collapsibility of the upper airways. Theoretically, the hypotonia of the upper-airway dilator muscles (except GG) during SWS (the red rectangle in Fig. 1, the only one which continues with two arrows) could result in higher increase of upper-airway resistance than upperairway collapsibility, i.e. despite the generally low upperairway muscle activity (except GG) during SWS, the ability to achieve high muscle activity levels during imminent threats of upper-airway collapse could be quite well preserved. After adding both influences (A) the SWS and (B) the beneficial upper-airway shapes it is possible to reach seemingly contradictory results (A) higher upper-airway resistance and (B) lower upper-airway collapsibility. However, this explanation is only theoretical with no supporting data.

There are some drugs, such as, sodium oxybate (SXB) or some antidepressants (e.g. trazodone, fluoxetine) which seem to be more beneficial for NREMs than REMs in OSAS patients (George et al. 2011, Veasey et al. 1999, Smales et al. 2015, Hanzel et al. 1991). These drugs can decrease whole-night AHI and also increase occurrence of SWS but they do not increase or even sometimes decrease occurrence of REMs. This may suggest that their primary effect is the increase of SWS, which subsequently leads to decrease of AHI. However, for example, protriptyline, one of the activating antidepressants, has a primary inhibitory effect on SWS (Wichniak et al. 2017) and yet is able to decrease AHI in OSAS patients (Hanzel et al. 1991). Moreover, both SXB and antidepressants are used for treatment of cataplexy (Lopez and Dauvilliers 2013); this supports the view that higher upper-airway muscle tone, or the decrease of AHI, is achieved directly without any relationship with SWS. In an animal model of OSAS (English Bulldog), the combination of trazodone and L-tryptophan lowers AHI in both REMs and NREMs, however, the occurrence of REMs tends to decrease (Veasey et al. 1999), probably because of the adverse effect of L-tryptophan to REMs (Bakalian and Fernstrom 1990). The same inhibitory effect on REMs is attributed to many antidepressants (e.g. also fluoxetine or protriptyline) (Wichniak et al. 2017). It is also worth mentioning that CPAP, which clearly acts on the upper airways, may also appear to have a stronger beneficial effect on NREMs than REMs, as the rebound of SWS is higher than the rebound of REMs in the first CPAP night (Brillante et al. 2012).

CPAP is regarded as a gold standard for OSAS 
treatment. Pharmacological intervention can be used occasionally, especially when there is CPAP intolerance together with depression comorbidity. However, effectiveness is highly variable, some patients do not respond to the treatment and some of them even show worsening of OSAS (Smales et al. 2015, Hanzel et al. 1991, Mendelson et al. 1991). For example, Hanzel et al. (1991) found a slight decrease in AHI-NREMs in 12 OSAS patients after 4 weeks with fluoxetine as well as with protriptyline (from $57 \pm 9 / \mathrm{h}$ to $34 \pm 6 / \mathrm{h}$ and $33 \pm 8 / \mathrm{h}$, respectively), however, one patient decreased AHI-NREMs from $46 / \mathrm{h}$ to $2 / \mathrm{h}$ with fluoxetine, other one decreased AHI-NREMs from $51 / \mathrm{h}$ to $7 / \mathrm{h}$ with protriptyline and there was also one patient who reached significant increase in AHI-NREMs with fluoxetine as well as with protriptyline (from $18 / \mathrm{h}$ to $49 / \mathrm{h}$ and $69 / \mathrm{h}$, respectively). Therefore, an individual patient approach is important here and it may be assumed that this will also be the case of potential new drugs specifically designed to treat OSAS in the future. Along with the falling cost of genome sequencing, it suggests the rise of personalized pharmacological treatment of OSAS in the future.

The current study does not take into account the presence of depression, the diet or the use of drugs which are potential confounding factors as they may affect SWS occurrence (Pillai et al. 2011, Wichniak et al. 2017, Afaghi et al. 2008). Depression occurs more frequently in both obese and OSAS patients. Reduced SWS was suggested as a genetic biomarker, i.e. predisposition, for major depressive disorder (Pillai et al. 2011). During depression, SWS is significantly longer than during remission (Pillai et al. 2011).

In conclusion, the current study found that SWS occurs more in the lateral body position than in supine position, i.e. in the position which is less prone to obstructive apnea exposure. This suggests that strong coincidence between SWS and low AHI is the result of the high instability of SWS to obstructive apnea exposure. The data also support the presence of SWS-rebound in OSAS patients in the lateral body position. Generally, the current study does not consider the effort to increase the occurrence of SWS by drugs as beneficial for OSAS patients, on the contrary it supports the increase of the upper-airway muscle tone as beneficial.

\section{Conflict of Interest}

There is no conflict of interest.

\section{References}

AFAGHI A, O'CONNOR H, CHOW CM: Acute effects of the very low carbohydrate diet on sleep indices. Nutr Neurosci 11: 146-154, 2008.

BAKALIAN MJ, FERNSTROM JD: Effects of L-tryptophan and other amino acids on electroencephalographic sleep in the rat. Brain Res 528: 300-307, 1990.

BERRY RB, BROOKS R, GAMALDO CE, HARDING SM, LLOYD RM, MARCUS CL, VAUGHN BV: The AASM Manual for the Scoring of Sleep and Associated Events: Rules, Terminology and Technical Specifications, Version 2.2. www.aasmnet.org. Darien, Illinois: American Academy of Sleep Medicine, 2015.

BITTENCOURT LRA, SUCHECKI D, TUFIK S, PERES C, TOGEIRO SM, BAGNATO MDC, NERY LE: The variability of the apnoea-hypopnoea index. J Sleep Res 10: 245-251, 2001.

BOUDEWYNS A, PUNJABI N, VAN DE HEYNING PH, DE BACKER WA, O'DONNELL CP, SCHNEIDER H, SMITH PL, SCHWARTZ AR: Abbreviated method for assessing upper airway function in obstructive sleep apnea. Chest 118: 1031-1041, 2000.

BRILLANTE R, COSSA G, LIU PY, LAKS L: Rapid eye movement and slow-wave sleep rebound after one night of continuous positive airway pressure for obstructive sleep apnoea. Respirology 17: 547-553, 2012.

CARBERRY JC, JORDAN AS, WHITE DP, WELLMAN A, ECKERT DJ: Upper airway collapsibility (Pcrit) and pharyngeal dilator muscle activity are sleep stage dependent. Sleep 39: 511-521, 2016.

EDWARDS BA, WHITE DP: Control of the pharyngeal musculature during wakefulness and sleep: implications in normal controls and sleep apnea. Head Neck 33 (Suppl 1): S37-S45, 2011.

ELLIOTT AR, SHEA SA, DIJK DJ, WYATT JK, RIEL E, NERI DF, CZEISLER CA, WEST JB, PRISK GK: Microgravity reduces sleep-disordered breathing in humans. Am J Respir Crit Care Med 164: 478-485, 2001.

GARVEY JF, PENGO MF, DRAKATOS P, KENT BD: Epidemiological aspects of obstructive sleep apnea. $J$ Thorac Dis 7: 920-929, 2015. 
GEORGE CF, FELDMAN N, ZHENG Y, STEININGER TL, GRZESCHIK SM, LAI C, INHABER N: A 2-week, polysomnographic, safety study of sodium oxybate in obstructive sleep apnea syndrome. Sleep Breath $\mathbf{1 5}$ : 13-20, 2011.

HANZEL DA, PROIA NG, HUDGEL DW: Response of obstructive sleep apnea to fluoxetine and protriptyline. Chest 100: 416-421, 1991.

HICKS A, CORI JM, JORDAN AS, NICHOLAS CL, KUBIN L, SEMMLER JG, MALHOTRA A, MCSHARRY DGP, TRINDER JA: Mechanisms of the deep, slow-wave, sleep-related increase of upper airway muscle tone in healthy humans. J Appl Physiol (1985) 122: 1304-1312, 2017.

IBER C, ANCOLI-ISRAEL S, CHESSON A JR, QUAN S: The AASM manual for the scoring of sleep and associated events: rules, terminology and technical specifications, Westchester, IL, American Academy of Sleep Medicine, 2007.

ISONO S, TANAKA A, ISHIKAWA T, TAGAITO Y, NISHINO T: Sniffing position improves pharyngeal airway patency in anesthetized patients with obstructive sleep apnea. Anesthesiology 103: 489-494, 2005.

ISONO S, TANAKA A, TAGAITO Y, ISHIKAWA T, NISHINO T: Influences of head positions and bite opening on collapsibility of the passive pharynx. J Appl Physiol (1985) 97: 339-346, 2004.

ISSA FG, SULLIVAN CE: The immediate effects of nasal continuous positive airway pressure treatment on sleep pattern in patients with obstructive sleep apnea syndrome. Electroencephalogr Clin Neurophysiol 63: 10-17, 1986.

JOOSTEN SA, EDWARDS BA, WELLMAN A, TURTON A, SKUZA EM, BERGER PJ, HAMILTON GS: The effect of body position on physiological factors that contribute to obstructive sleep apnea. Sleep 38: 1469-1478, 2015.

JORDAN AS, WHITE DP, LO YL, WELLMAN A, ECKERT DJ, YIM-YEH S, EIKERMANN M, SMITH SA, STEVENSON KE, MALHOTRA A: Airway dilator muscle activity and lung volume during stable breathing in obstructive sleep apnea. Sleep 32: 361-368, 2009.

KOUTSOURELAKIS I, LAMPROU K, VAGIAKIS E, ZAKYNTHINOS S: Resolution of apnoeas in slow wave sleep. Sleep Breath 20: 819-820, 2016.

LOPEZ R, DAUVILLIERS Y: Pharmacotherapy options for cataplexy. Expert Opin Pharmacother 14: 895-903, 2013.

MALHOTRA A, TRINDER J, FOGEL R, STANCHINA M, PATEL SR, SCHORY K, KLEVERLAAN D, WHITE DP: Postural effects on pharyngeal protective reflex mechanisms. Sleep 27: 1105-1112, 2004.

MARQUES M, GENTA PR, SANDS SA, AZARBAZIN A, DE MELO C, TARANTO-MONTEMURRO L, WHITE DP, WELLMAN A: Effect of sleeping position on upper airway patency in obstructive sleep apnea is determined by the pharyngeal structure causing collapse. Sleep 40: pii: zsx005, 2017.

MCSHARRY DG, SABOISKY JP, DE YOUNG P, MATTEIS P, JORDAN AS, TRINDER J, SMALES E, HESS L, GUO M, MALHOTRA A: A mechanism for upper airway stability during slow wave sleep. Sleep 36: 555-563, 2013.

MCSHARRY DG, SABOISKY JP, DEYOUNG P, JORDAN AS, TRINDER J, SMALES E, HESS L, CHAMBERLIN NL, MALHOTRA A: Physiological mechanisms of upper airway hypotonia during REM sleep. Sleep 37 : 561-569, 2014.

MENDELSON WB, MACZAJ M, HOLT J: Buspirone administration to sleep apnea patients. J Clin Psychopharmacol 11: 71-72, 1991.

OKSENBERG A, KHAMAYSI I, SILVERBERG DS, TARASIUK A: Association of body position with severity of apneic events in patients with severe nonpositional obstructive sleep apnea. Chest 118: 1018-1024, 2000.

OTSUKA R, ONO T, ISHIWATA Y, KURODA T: Respiratory-related genioglossus electromyographic activity in response to head rotation and changes in body position. Angle Orthod 70: 63-69, 2000.

PALLAYOVA M, DONIC V, GRESOVA S, PEREGRIM I, TOMORI Z: Do differences in sleep architecture exist between persons with type 2 diabetes and nondiabetic controls? J Diabetes Sci Technol 4: 344-352, 2010.

PEREGRIM I, GREŠOVÁ S, PALLAYOVÁ M, FULTON BL, ŠTIMMELOVÁ J, BAČOVÁ I, MIKUL'AKOVÁ A, TOMORI Z, DONIČ V: Does obstructive sleep apnea worsen during REM sleep? Physiol Res 62: 569-575, 2013. 
PILLAI V, KALMBACH DA, CIESLA JA: A meta-analysis of electroencephalographic sleep in depression: evidence for genetic biomarkers. Biol Psychiatry 70: 912-919, 2011.

RAO MN, BLACKWELL T, REDLINE S, STEFANICK ML, ANCOLI-ISRAEL S, STONE KL, FOR THE OSTEOPOROTIC FRACTURES IN MEN (MROS) STUDY GROUP: Association between sleep architecture and measures of body composition. Sleep 32: 483-490, 2009.

RATNAVADIVEL R, CHAU N, STADLER D, YEO A, MCEVOY RD, CATCHESIDE PG: Marked reduction in obstructive sleep apnea severity in slow wave sleep. J Clin Sleep Med 5: 519-524, 2009.

REDLINE S, KIRCHNER HL, QUAN SF, GOTTLIEB DJ, KAPUR V, NEWMAN A: The effects of age, sex, ethnicity, and sleep-disordered breathing on sleep architecture. Arch Intern Med 164: 406-418, 2004.

REUTRAKUL S, MOKHLESI B: Obstructive sleep apnea and diabetes: a state of the art review. Chest 152: 1070-1086, 2017.

SMALES ET, EDWARDS BA, DEYOUNG PN, MCSHARRY DG, WELLMAN A, VELASQUEZ A, OWENS R, ORR JE, MALHOTRA A: Trazodone effects on obstructive sleep apnea and non-REM arousal threshold. Ann Am Thorac Soc 12: 758-764, 2015.

TANGEL DJ, MEZZANOTTE WS, SANDBERG EJ, WHITE DP: Influences of NREM sleep on the activity of tonic vs. inspiratory phasic muscles in normal men. $J$ Appl Physiol (1985) 73: 1058-1066, 1992.

TANGEL DJ, MEZZANOTTE WS, WHITE DP: Influence of sleep on tensor palatini EMG and upper airway resistance in normal men. $J$ Appl Physiol (1985) 70: 2574-2581, 1991.

TRINDER J, KAY A, KLEIMAN J, DUNAI J: Gender differences in airway resistance during sleep. $J$ Appl Physiol (1985) 83: 1986-1997, 1997.

VEASEY SC, FENIK P, PANCKERI K, PACK AI, HENDRICKS JC: The effects of trazodone with L-tryptophan on sleep-disordered breathing in the English bulldog. Am J Respir Crit Care Med 160: 1659-1667, 1999.

WICHNIAK A, WIERZBICKA A, WALĘCKA M, JERNAJCZYK W: Effects of antidepressants on sleep. Curr Psychiatry Rep 19: 63-69, 2017.

WIEGAND DA, LATZ B, ZWILLICH CW, WIEGAND L: Geniohyoid muscle activity in normal men during wakefulness and sleep. $J$ Appl Physiol (1985) 69: 1262-1269, 1990.

ZHU K, BRADLEY TD, PATEL M, ALSHAER H: Influence of head position on obstructive sleep apnea severity. Sleep Breath 21: 821-828, 2017. 